This paper reports a study into features of the formation of structures of permanent butt joints of plates with a thickness of $1.5 \mathrm{~mm}$ made from the high-strength aluminum alloy 7075 of the $\mathrm{Al}-\mathrm{Zn}-\mathrm{Mg}-\mathrm{Cu}$ system. Welding by melting these joints was performed using three techniques: laser, microplasma, and hybrid laser-microplasma. To implement the latter two, a compressed arc on a multipolar asymmetric current was used. The purpose of the research was to establish the tendency to the formation of characteristic defects and the possibility of their elimination. It has been determined that during laser welding a small ( $\sim 5 \%)$ volumetric fraction of defects in the form of pores is formed, residual welding deformations are minimized. There is a decrease in the hardness of the melted metal by $15 \%$ with a simultaneous increase in the hardness of the heat-affected zone (HAZ) by $8 . . .12 \%$ relative to the base metal. In the melted metal, cavities up to $100 \mu \mathrm{m}$ in size are formed, which are the center of the origin of hot cracks with a length of 25-30 $\mu \mathrm{m}$. There are oxide inclusions in the root part of the seam. With microplasma welding, the volume fraction of defects of the melted metal in the form of pores with a size of 10...105 um increases (up to 25\%). The hardness of the melted metal is reduced by $30 \%$ with the hardness of the $\mathrm{HAZ}$ metal close to the base metal. In lasermicroplasma welding, the volumetric fraction of defects of the melted metal in the form of pores with a size of 15...25 um is reduced to $5 \%$. The hardness of the melted metal is reduced by $15 . .20 \%$ with the hardness of the HAZ metal close to the base metal. In the lower part of the melted metal, cavities of $\sim 100$ um are formed. No microcracks were found in the seam metal. Analysis of the research results showed the advantage of the laser-microplasma technique. This method reduces the use of laser energy by $40 . .50 \%$, the lifetime of the welding pool (0.03...0.05 s) approaches laser welding, it eliminates the danger of burnout of alloying elements Keywords: high-strength alloy 7075 , laser welding, microplasma welding, laser-microplasma welding, metal grains, chemical composition

Received date 14.12.2021 Accepted date 15.02.2022 Published date 27.02.2022
How to Cite: Korzhyk, V., Khaskin, V., Grynyuk, A., Peleshenko, S., Kvasnytskyi, V., Fialko, N., Berdnikova, O., Illiashenko, Y., Shcheretskiy, V., Yao, Y. (2022).Comparison of the features of the formation of joints of aluminum alloy 7075 ( $\mathrm{Al}-\mathrm{Zn}-\mathrm{Mg}-\mathrm{Cu}) \mathrm{by}$ laser, microplasma, and laser-microplasma welding. Eastern-European Journal of Enterprise Technologies, 1 (12 (115)), $38-47$. doi: https://doi.org/10.15587/1729-4061.2022.253378

\section{Introduction}

Aluminum alloys are widely used in modern industry for the manufacture of lightweight structures with high strength
UDC 621.791 .755 .5

DOI: $10.15587 / 1729-4061.2022 .253378$

\title{
COMPARISON OF THE FEATURES OF THE FORMATION OF JOINTS OF ALUMINUM ALLOY 7075 (Al-Zn-Mg-Cu) BY LASER, MICROPLASMA, AND LASER-MICROPLASMA WELDING
}

Volodymyr Korzhyk

Doctor of Technical Sciences, Professor, Head of Department, Corresponding Member of the National Academy of Sciences of Ukraine*

VIadyslav Khaskin

Corresponding author

Doctor of Technical Sciences, Leading Researcher* E-mail: khaskin1969@gmail.com

Andri i Gryny u $\mathrm{PhD}$, Researcher*

Sviatoslav Peleshenko

Postgraduate Student***

Viktor Kvasnytskyi Doctor of Technical Sciences, Professor***

Nataliia Fialko Doctor of Technical Sciences, Professor, Corresponding Member of the National Academy of Sciences of Ukraine Department of Thermophysics of Energy-Efficient Heat Technologies Institute of Engineering Thermophysics of the National Academy of Sciences of Ukraine Mariyi Kapnist (Zhelyabova) str., 2A, Kyiv, Ukraine, 03057

Olena Berdnikova

Doctor of Technical Sciences, Leading Researcher Department of Physical and Chemical Research of Materials** Yevhenii IIIiashenko Leading Engineer*

Volodymyr Shcheretskiy $\mathrm{PhD}$, Senior Researcher

Department of Composite Materials

Physico-Technological Institute of Metals and Alloys of the National Academy of Science of Ukraine Akademika Vernadskoho str., 34/1, Kyiv, Ukraine, 03142 Y uhui Y ao Engineer

Shenzhen Hanzhizi Science and Technology Co., Ltd. 6th Floor, Building B, Bantian International Center, 5 Huancheng South Road, Longgang District, Shenzhen, Guangdong, China

*Department of Electrothermal Processing Material** $\star *$ E. O. Paton Electric Welding Institute of the National Academy of Sciences of Ukraine

Kazymyra Malevychastr., 11, Kyiv, Ukraine, 03150 $* * *$ Department of Welding Production National Technical University of Ukraine «lgor Sikorsky Kyiv Polytechnic Institute» Peremohy ave., 37, Kyiv, Ukraine, 03056

and corrosion resistance. Such structures include articles of instrument engineering, chemical and food industries, electric power and electronic technologies, transport, etc. [1]. In the manufacture of such structures, it is often necessary to 
execute high-quality non-detachable joints [2]. For this purpose, various welding techniques are used [3]. In the case of the manufacture of thin-walled non-detachable structures, it is advisable to use such welding techniques that provide local thermal heating of the weld area. For example, laser, plasma, or hybrid laser arc welding techniques [4].

In the manufacture of those structures, of particular interest is the possibility of using high-strength aluminum alloys. Such alloys make it possible to create lightweight structures with increased mechanical properties, which makes their use in modern industry relevant. Among the high-strength aluminum alloys, the most interesting are the alloys of the Al-Zn-Mg-Cu system (7xxx series), which have the highest mechanical properties. However, welding such alloys is difficult due to their tendency to form hot cracks and pores. Therefore, studies of structure formation during welding of thin-walled joints from these alloys using concentrated energy sources are relevant.

\section{Literature review and problem statement}

To connect thin-sheet aluminum alloys, both traditional (arc or plasma) techniques of fusion welding, and more modern (laser and hybrid laser-plasma) can be used. When using arc welding techniques, the width of the seam typically exceeds the depth, which is due to the convective mechanism of metal melting. Work [5] shows that the intensity of such heat exchange and the flow of liquid metal in the welding pool are affected by alloying elements that act as surfactants. In addition, the influence is exerted by the surface temperature, therefore, the welding parameters. In work [6], it is shown that when welding with a free-burning arc in the convective flow of the metal of the welding pool, the force of the surface tension gradient and the electromagnetic force prevail. The same penetration can be obtained by welding using laser and laser-plasma techniques [7]. At the same time, the dominant force factor determining the hydrodynamics of the melt is the Marangoni force. The formation of the molten zone in all the cases considered is mainly influenced by convective energy transfer. Its shape and the amount of energy invested can lead to the formation of hot cracks (especially when welding high-strength alloys of type 7075) [8]. More effective is the use of laser and laser-plasma welding with such a melting at which the width of the penetration is less than the depth. This type of penetration is called deep and is characterized by the formation of a vapor-gas channel [9]. Features of the existence of a vapor-gas channel are associated with its pulsations, which can contribute to the appearance of pores in the melted metal [10]. The formation of cracks is associated with an increase in the crystallization rate of fusible eutectics caused by an increase in the welding speed [11].

Thus, with laser, arc, and hybrid techniques for welding thin-sheet aluminum alloys, the following issues may arise [12]:

- obtaining compounds of different strength with the base metal, due to the difference in the size of the grains of the seam metal, the fusion zone of the seam with the base metal, the heat-affected zone (HAZ), and the base metal;

- the formation of cuts on the surface of the seam along the fusion zone, caused by the short lifetime of the welding pool in the liquid state and the lack of the possibility of normal spreading of the liquid metal until its crystallization;
- the appearance of pores in the seam metal associated with a change in the solubility of hydrogen in an aluminum alloy at different temperatures;

- the occurrence of hot cracks due to the presence of eutectic compounds in the seam metal and changes in the conditions of their solidification from molten metal at different crystallization rates due to different linear welding energies.

The joints of high-strength aluminum alloys of the $7 \mathrm{xxx}$ series are more prone to the formation of cracks and pores. In work [8], it is noted that evaporation during laser welding leads to a change in the concentration of volatile elements of magnesium and zinc. This changes the rate of crystallization of the weld and, consequently, the tendency to hot cracking. This effect is greatly influenced by the speed of welding. In [13], it is shown that the alloys of the $7 \mathrm{xxx}$ series have poor weldability due to their high tendency to crack formation and the coefficient of thermal expansion, as well as the low evaporation temperature of the alloying elements $\mathrm{Zn}$ and $\mathrm{Mg}$. This contributes to the formation of welding defects such as cracks and porosity. Similar defects can also occur in the case of welding deformable alloys of other series with lower strength [14]. In addition, when welding alloyed aluminum alloys in a melted metal, oxide inclusions are also possible. Recently, a series of approaches to minimizing and eliminating these defects have been developed. Basically, such approaches are focused on welding with through penetration with the formation of a through channel (keyhole) [14]. In the case of welding without through melting and keyhole formation, the risk of pores in the lower part of the seam increases. However, sometimes there is a need to execute seams without through penetration. An example would be a sealing ring seam when welding flanges or manufacturing parts of small diameters.

In the reviewed works, there are unresolved issues related to the peculiarities of the formation of seams without through penetration. First of all, this concerns the occurrence of characteristic defects and the proposal of ways to eliminate them. The literature does not contain information on the metallurgical features of the formation of compounds of high-strength aluminum alloys by seams of this type and on the choice of the optimal technology for obtaining a butt sealing seam with non-through penetration.

\section{The aim and objectives of the study}

The purpose of this study is to define the metallurgical features in the formation of welded joints by non-through butt joints, the tendency to form characteristic defects and the possibility of their elimination.

To accomplish the aim, the following tasks have been set:

- to determine the metallurgical features in the formation of compounds by the laser technique;

- to determine the metallurgical features in the formation of compounds by the microplasma technique;

- to determine the metallurgical features in the formation of compounds by the laser-microplasma technique.

\section{The study materials and methods}

The studied joints were obtained by butt welding with a non-through melting of plates with a thickness of $1.5 \mathrm{~mm}$ made from the high-strength aluminum alloy 7075 . Laser, 
microplasma, and laser-microplasma techniques were used to perform them. The following procedure of making and investigating such compounds was adopted:

- selection of mode parameters according to the criterion for the formation of a joint with the seam surface without characteristic defects in the form of surface pores, cracks, and undercuts, and welding by the selected techniques;

- production of templets for metallographic studies by the methods of optical and analytical scanning electron microscopy;

- determine the size of the melted part of the metal, a heat-affected zone (HAZ), and the value of the metal grains in these zones;

- measurement of micro hardness (by $1 / 3$ of the depth of penetration) at a load of $100 \mathrm{~g}$; determine the structure, structural features, and defects of the metal in the melted part and HAZ;

- determine the presence of oxide inclusions and changes in the content of $\mathrm{Mg}, \mathrm{Mn}, \mathrm{Zn}$ in the metal of the remelted part and HAZ in comparison with the base metal;

- determine the presence and size of internal pores and cracks, as well as the causes of their occurrence.

To conduct experiments on the selection of modes of laser, microplasma, and hybrid laser-microplasma welding, samples were made of the high-strength alloy 7075 . Table 1 gives both the literature data on the chemical composition of this alloy and the data that we acquired experimentally. The latter are measurements for individual elements, performed by the method of X-ray spectral microanalysis. This method determined the content of some elements of the alloy both inte- grally and in the volume of individual grains. The alloy 7075 was used to fabricate plates with a size of $50 \times 50 \times 1.5 \mathrm{~mm}$, which were welded butt-to-face, focusing on the maximum equal penetration depth of about $0.5 \ldots 0.7 \mathrm{~mm}$.

To weld the samples, the equipment described in [15] was used. The choice of parameters of welding modes was carried out according to the criteria of qualitative formation of the upper roller of the seam without cracks, surface pores, and undercuts, obtaining a penetration depth of about 0.5...0.7. The main parameters of the modes are given in Table 2 .

Grain size $D g$ was determined by optical microscopy as the ratio of its height $h$ to length 1 . In the base metal, the grain size is $D g=(10 \ldots 20) \times(25 \ldots 70) \mu \mathrm{m}$, shape coefficient $\curvearrowleft=l / h=2.5 \ldots 3.5$. Microhardness HV at a load of $100 \mathrm{~g}$ is within $1100 \ldots 1240 \mathrm{MPa}$. Erections of the string type $l_{B}=15 \ldots 35 \mu \mathrm{m}$ in the form of chains measuring $35 \ldots 75 \mu \mathrm{m}$ were identified (Fig. 1).

To carry out metallographic analysis, transverse templets were cut out of the resulting compounds and micro sections were made. In this case, ion-vacuum etching was used. The results of the completed joints were investigated by the methods of optical (microscopes Versamet-2 and Neophot-31) and analytical scanning electron (microscope SEM-515 of PHILIPS, Holland) microscopy. Studies were carried out at the following sample sites: remelted melt of seam $\rightarrow$ weld metal $\rightarrow \mathrm{HAZ} \rightarrow$ base metal. With the help of optical microscopy, structural changes were examined. Microhardness was measured using the LM-400 microhard meter (LECO series). Using analytical scanning electron microscopy, the chemical composition (general and local point analysis) was determined.

Content of elements (wt. \%) in the high-strength aluminum alloy 7075

Table 1

\begin{tabular}{|l|c|c|c|c|c|c|c|c|c|c|}
\hline $\begin{array}{c}\text { Determination } \\
\text { technique }\end{array}$ & $\mathrm{Al}$ & $\mathrm{Si}$ & $\mathrm{Fe}$ & $\mathrm{Cu}$ & $\mathrm{Mn}$ & $\mathrm{Mg}$ & $\mathrm{Cr}$ & $\mathrm{Zn}$ & $\mathrm{Ti}$ & $\mathrm{Other}$ \\
\hline Alloy reference & base & to 0.40 & to 0.50 & $1.2-2.0$ & to 0.30 & $2.1-2.9$ & $0.18-0.28$ & $5.1-6.1$ & to 0.20 & to 0.15 \\
\hline General analysis & $89.26-90.74$ & $0.26-0.95$ & - & $1.71-1.96$ & $0.06-0.43$ & $0.98-1.28$ & - & $5.84-6.87$ & - & - \\
\hline $\begin{array}{l}\text { Grain volume } \\
\text { analysis }\end{array}$ & $89.35-90.74$ & $0.26-0.68$ & - & $1.42-1.91$ & $0.05-0.28$ & $0.95-1.28$ & - & $6.12-6.97$ & - & - \\
\hline $\begin{array}{l}\text { Inclusions in the } \\
\text { volume of grains }\end{array}$ & - & $0.08-1.7$ & $0.61-30.27$ & $3.13-9.29$ & $1.26-2.93$ & $0.04-5.76$ & $1.69-12.83$ & $1.49-13.31$ & - & - \\
\hline
\end{tabular}

Table 2

The main parameters of the modes of welding samples made from alloy 7075

\begin{tabular}{|l|c|c|c|c|c|c|}
\hline \multirow{2}{*}{ Welding technique } & \multirow{2}{*}{$\begin{array}{c}\text { Power of laser } \\
\text { radiation, } \mathrm{W}\end{array}$} & \multicolumn{2}{|c|}{ Microplasma arc power, $\mathrm{W}$} & \multirow{2}{*}{$\begin{array}{c}\text { Welding rate } V, \\
\mathrm{~mm} / \mathrm{s}\end{array}$} & \multicolumn{2}{|c|}{ Gas consumption $($ Ar), $1 / \mathrm{min}$} \\
\cline { 6 - 8 } & & Direct polarity & Inverse polarity & & Plasma-forming & Protective \\
\hline Laser & 400 & - & - & 66.7 & - & 8 \\
\hline Microplasma & - & 900 & 550 & 5 & 0.3 & 18 \\
\hline Laser-microplasma & 250 & 1200 & 600 & 66.7 & 10 & 30 \\
\hline
\end{tabular}

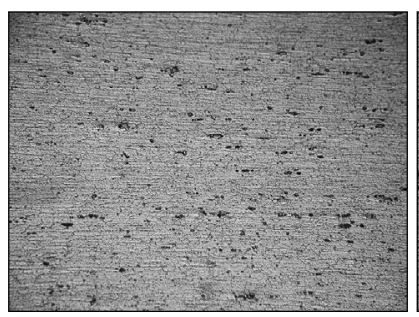

a

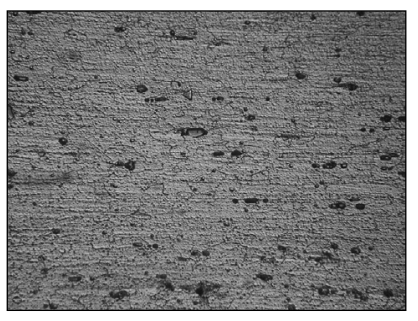

Fig. 1. Base metal structure (alloy 7075) at magnification: $a-\times 250 ; b-\times 500$ 


\section{Results of studying the metallurgical features} in the formation of compounds of alloy 7075

\section{1. Laser welding}

The main features in the formation of non-through penetration by the laser technique are associated with the stability of the existence of a steam-gas channel. Obviously, the improvement of the formation of the penetration is facilitated by a decrease in the size and increase in the frequency of pulsations of this channel. The very presence of a steam-gas channel contributes to the formation of deep penetration, a distinctive feature of which is the excess of depth over width (Fig. 2, $a$ ). In a given case, the penetration depth was $0.68 \ldots 0.74 \mathrm{~mm}$; width $-0.65 \ldots 0.70 \mathrm{~mm}$. Along the fusion line, grains of elongated dendrites are observed, which allows us to talk about a fusion zone with a width of $12 \ldots 16 \mu \mathrm{m}$ (Fig. 2, $b$ ).

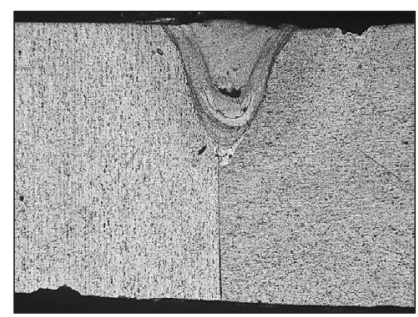

$a$

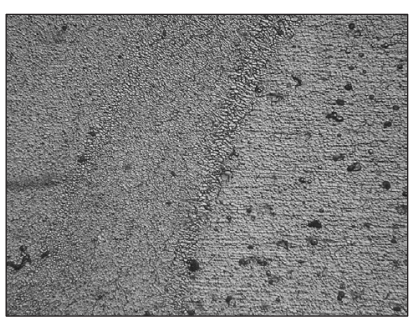

$b$
Fig. 2. Structures of laser penetration: $a$-general view of penetration, $\times 50 ; b-$ fusion zone with base metal, $\times 500$

In the melted metal, individual pores with a diameter of about $10 \mu \mathrm{m}$ are observed. Below the middle of the seam, a cavity of approximately $25 \times 100 \mu \mathrm{m}$ in size and surrounding microcracks with a length of $L_{c r}=25 \ldots 30 \mu \mathrm{m}$ (Fig. 3, $a$ ) were detected. The total volume fraction $\left(V_{D}\right)$ of defects in the seam metal is about $5 \%$. In the center of the metal of the seam, the structure is of equal-axis shape with a grain size of $D g=10 \ldots 25 \mu \mathrm{m}$ (Fig. 2). The microhardness in the center of the seam is $H V=1130 \ldots 1140 \mathrm{MPa}$ (Fig. 4). Closer to the fusion line in the melted metal there is a structure with grains of elongated shape, having a size of $D g=(10 \ldots 15) \times(30 \ldots 35) \mu \mathrm{m}$ at $H V=980 \mathrm{MPa}($ Fig. 3, 4). In the lower part of the melted metal, oxide film secretions were revealed, repeating the shape of the fusion line in the root part. These oxide discharges of the line type with a size $l_{\mathrm{Al} 2 \mathrm{O} 3}=25 \ldots 35 \mu \mathrm{m}$ are arranged in the form of chains up to $L_{\mathrm{SAl} 2 \mathrm{O} 3}=50 \ldots 120 \mu \mathrm{m}$ (Fig. 3, $a$ ).

The width of the HAZ is $h_{H A Z}=130 \ldots 150 \mu \mathrm{m}$ (Fig. 2). The grain size in HAZ is $D g=(5 \ldots 20) \times(26 \ldots 50) \mu \mathrm{m}$, grain shape coefficient $\mathfrak{\wp = l} / h=2.5 . .5$. Microhardness compared to melted and base metal increased to $H V=1190 \ldots 1350 \mathrm{MPa}$ (Fig. 4). In HAZ near the fusion line, there are separate microcracks with a length of $L_{c r}=10 \ldots 20 \mu \mathrm{m}$ (Fig. $3, b$ ).

In the area of connection of the two plates of alloy 7075, the grain size is $D g=(5 \ldots 15) \times(40 \ldots 70) \mu \mathrm{m}$ on the left plate side, and $D g=(5 \ldots 15) \times(30 \ldots 35) \mu \mathrm{m}$ on the right side (Fig. 2, $a)$. There is a good connection of the plates without the formation of a gap.

$\mathrm{X}$-ray spectral microanalysis of the content of individual elements in the metal of the joint and the base metal was carried out both integrally, according to the area of the corresponding zone, and in the volume of individual grains (Table 3).

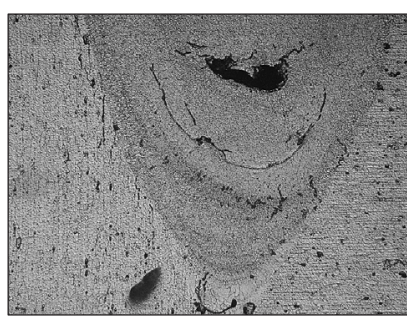

a

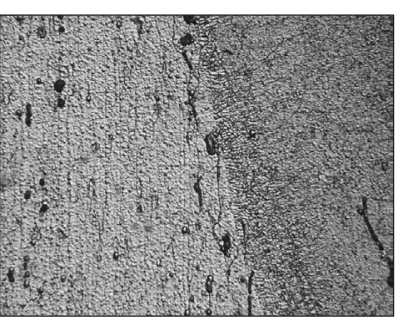

$b$
Fig. 3. Defective areas: $a-$ in melted metal, $\times 250$; $b-$ in the main metal near the fusion line, $\times 500$

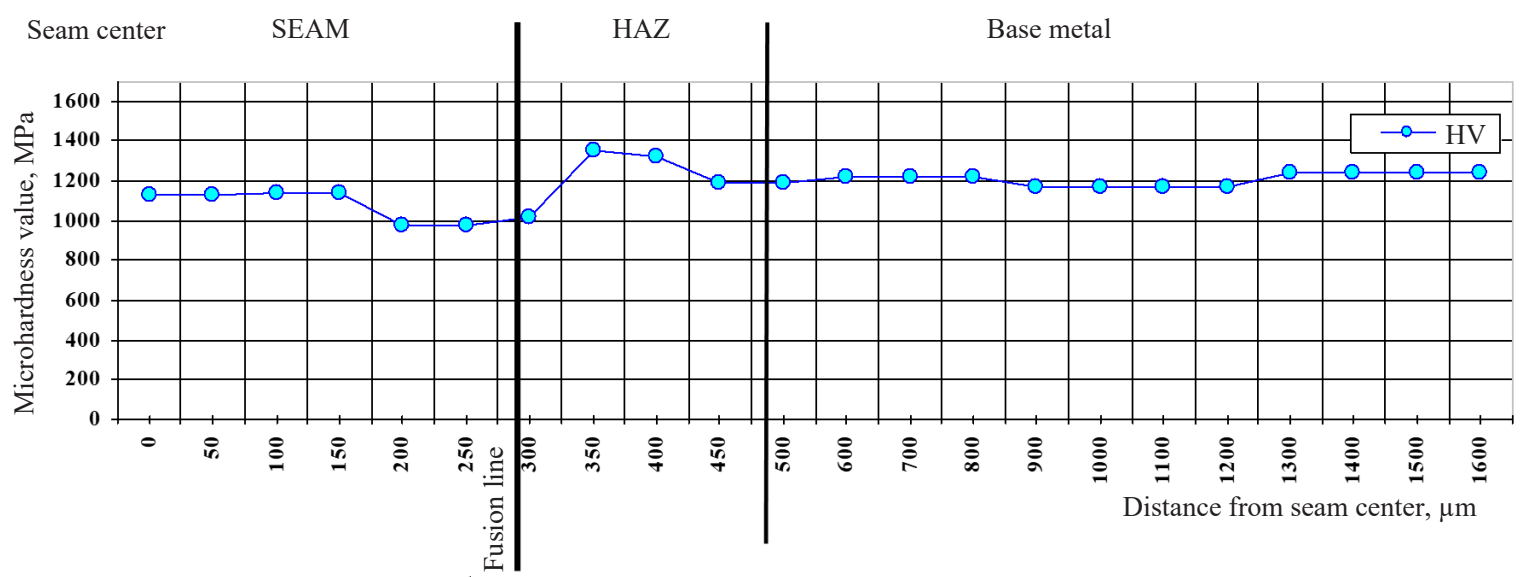

Fig. 4. Hardness distribution from the penetration axis towards the base metal in a laser-made joint

Results of determining the content of the main elements by X-ray spectral microanalysis technique (laser welding)

\begin{tabular}{|c|c|c|c|c|c|c|c|}
\hline \multirow{2}{*}{ Study area } & \multirow{2}{*}{ Analysis type } & \multicolumn{6}{|c|}{ Elemental content. wt \% } \\
\hline & & $\mathrm{Al}$ & $\mathrm{Mg}$ & $\mathrm{Si}$ & $\mathrm{Mn}$ & $\mathrm{Cu}$ & $\mathrm{Zn}$ \\
\hline Remelted metal & General analysis & $89.74-90.07$ & $1.08-1.09$ & $0.40-0.51$ & $0.22-0.32$ & $1.88-2.11$ & $6.25-6.33$ \\
\hline Remelted metal & Grain volume analysis & $85.43-87.61$ & $1.10-1.13$ & 0.53 & 0.35 & $2.59-3.35$ & $7.78-10.10$ \\
\hline HAZ & General analysis & $89.17-89.25$ & $1.09-1.14$ & $0.32-0.43$ & $0.12-0.13$ & $1.99-2.06$ & $6.87-7.20$ \\
\hline Base metal & General analysis & $89.26-90.52$ & $1.0-1.13$ & $0.42-0.52$ & $0.16-0.43$ & $1.73-1.78$ & $6.17-6.87$ \\
\hline Base metal & Grain volume analysis & $89.35-89.83$ & $1.06-1.28$ & $0.38-0.62$ & $0.05-0.23$ & $1.73-1.84$ & $6.57-6.97$ \\
\hline
\end{tabular}


General (integral) studies have shown a tendency to increase the $\mathrm{Zn}$ content in HAZ. Local analysis of the content of elements in the volume of grains showed an increase in the content of $\mathrm{Cu}$ and $\mathrm{Zn}$ in the melted seam metal. The lack of the possibility of the through passage of laser radiation provokes the formation of large cavities in the root part of the metal of the seam.

Despite the ingress of air from the joint between the welded plates, the short lifetime of the welding pool $(0.02 \ldots 0.04 \mathrm{~s})$ during laser welding minimizes the formation of cavities in the lower (root) part of the metal seam.

\section{2. Microplasma welding}

The main features in the formation of non-through melting by the microplasma technique are associated with the pressure of the compressed electric arc on the metal of the welding pool formed by it. The greater this pressure, the deeper the melting. However, an excessive increase in this parameter can contribute to the appearance of internal pores and hot cracks. Therefore, when using microplasma welding, the width of the penetration usually exceeds the depth. In the experiments conducted, the depth of penetration was $0.56 \ldots 0.72 \mathrm{~mm}$, width $-1.5 \ldots 1.7 \mathrm{~mm}$ (Fig. 5, a). The fusion line is not clearly expressed and is a zone of about $50 \ldots 80 \mu \mathrm{m}$ (Fig. 5, $b$ ).

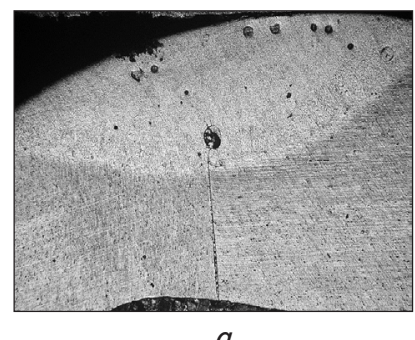

$a$

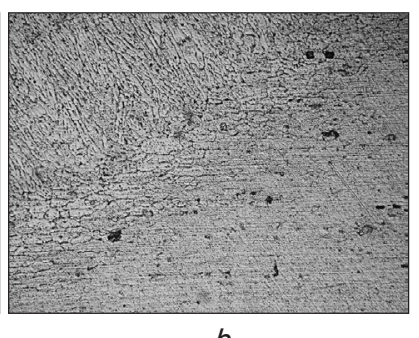

Fig. 5. Structures of microplasma penetration: $a$ - general view, $\times 50 ; b-$ fusion zone with base metal, $\times 250$

In the melted metal, individual pores with a diameter of 10 to $105 \mu \mathrm{m}$ are observed (Fig. $6 a$ ). The total volume fraction of defects in melted metal $\left(V_{D}\right)$ is about $25 \%$. The pores are localized mainly in the upper part of the seam (Fig. 5, $a$ ). In the lower part of the seam there is a single large pore measuring $90 \ldots 110 \mu \mathrm{m}$ (Fig. 6), which acts as the center of the origin of microcracks with a length of $30 \ldots 120 \mu \mathrm{m}$ (Fig. 6, $b$ ).
In the center of the metal of the seam there is a structure with grains of equal-axis shape with a size of $D g=20 \ldots 30 \mu \mathrm{m}$ having a microhardness $H V=822 \ldots 1130 \mathrm{MPa}$ (Fig. 7). Closer to the fusion line in the melted metal, a structure with grains of a longer shape with a size of $D g=(15 \ldots 20) \times(30 \ldots 70) \mu \mathrm{m}$ having a microhardness $H V=1080 \ldots 1100 \mathrm{MPa}$ (Fig. 5, $a$, Fig. 7) was observed. Oxide film secretions were not detected.

The width of HAZ is $h_{H A Z}=120 \ldots 300 \mu \mathrm{m}$ (Fig. 5). The grain size in $\mathrm{HAZ}$ is $D g=(10 \ldots 25) \times(25 \ldots 100) \mu \mathrm{m}$ with an increase in microhardness compared to the seam metal to $H V=1190 \ldots 1250 \mathrm{MPa}$ (Fig. 7).

In the region of the junction of two welded plates of alloy 7075, the size of the metal grains is: for the left plate, $D g(15 \ldots 20) \times(30 \ldots 50) \mu \mathrm{m}$, and for the right $D g=(10 \ldots 25) \times(45 \ldots 50) \mu \mathrm{m}$.

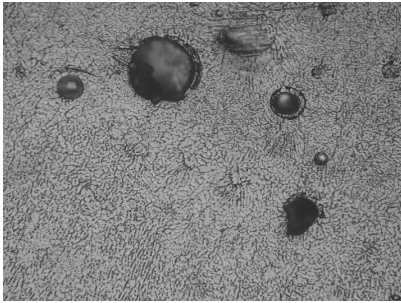

$a$

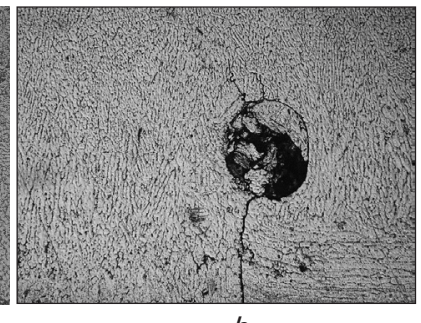

b
Fig. 6. Defective areas in the metal remelted by the microplasma technique $(\times 250): a-$ individual pores; $b$ - cavity in the root zone

$\mathrm{X}$-ray spectral microanalysis of the content of individual elements in the metal of the compound and the base metal was carried out integrally according to the area of the corresponding zone, in the volume of individual grains, as well as along the grain boundaries (Table 4).

General (integral) studies have shown that the content of the analyzed elements in the melted metal is approximately at the level of the base metal. However, inclusions of a globular form up to $10 \mu \mathrm{m}$ in size were identified (Fig. 6). Chemical analysis revealed that in the inclusions the content of the considered elements is markedly different: $2.12 \ldots 2.23 \% \mathrm{Mg}, 0.26 \ldots . .0 .39 \% \mathrm{Si}$, to $0.19 \% \mathrm{Mn}, 3.28 \ldots 6.44 \%$ $\mathrm{Cu}, 16.38 \ldots 30.55 \% \mathrm{Zn}$. In HAZ, the integral analysis showed the content of the elements close enough to the base metal. A more detailed analysis revealed a decrease in the content of $\mathrm{Cu}$ and $\mathrm{Zn}$ in the volume of grains with their redistribution along the boundaries.

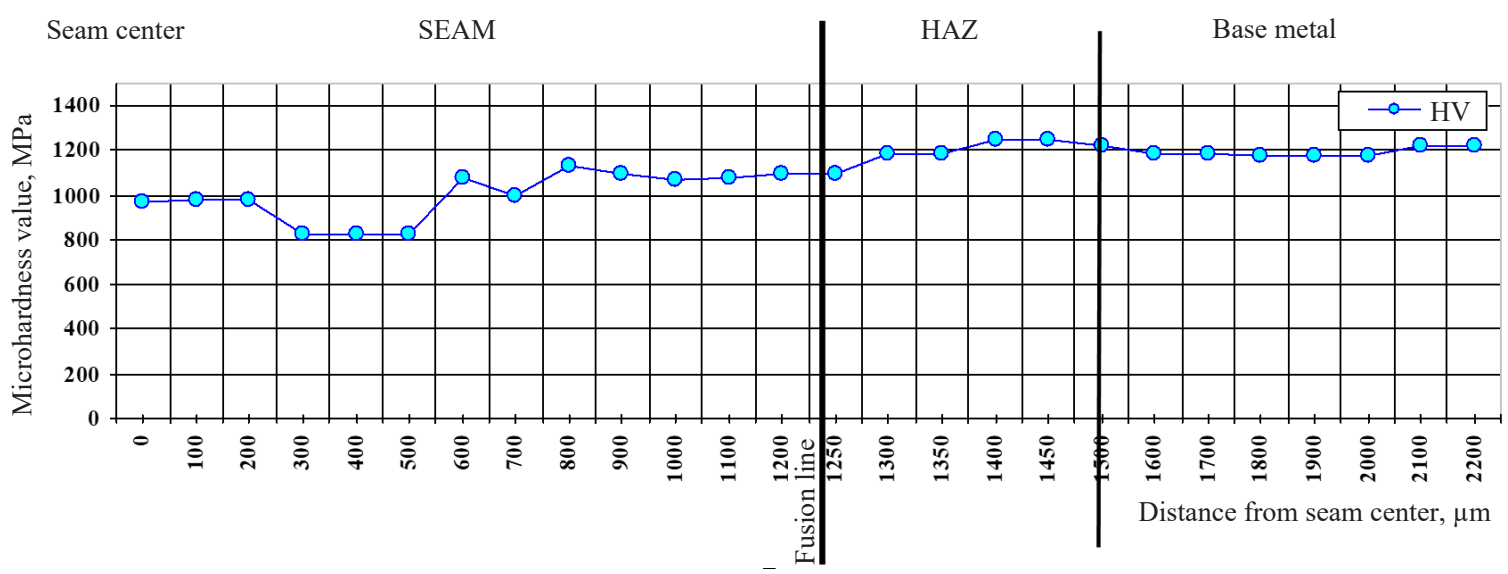

Fig. 7. Distribution of hardness from the axis of the penetration to the base metal in the joint made by the microplasma technique 
Table 4

Results of determining the content of the main elements by X-ray spectral microanalysis (microplasma welding)

\begin{tabular}{|c|c|c|c|c|c|c|c|}
\hline \multirow{2}{*}{ Study area } & \multirow{2}{*}{ Analysis type } & \multicolumn{5}{|c|}{ Elemental content, wt \% } \\
\cline { 3 - 8 } & & $\mathrm{Al}$ & $\mathrm{Mg}$ & $\mathrm{Si}$ & $\mathrm{Mn}$ & $\mathrm{Cu}$ & $\mathrm{Zn}$ \\
\hline Remelted metal & General analysis & $89.98-90.37$ & $0.94-1.04$ & $0.43-0.60$ & 0.10 & $1.5-2.0$ & $6.48-6.70$ \\
\hline Remelted metal & Analysis in grain volume & $89.09-91.21$ & $0.84-1.06$ & $0.68-0.70$ & 0.28 & $1.02-1.89$ & $6.22-6.99$ \\
\hline Remelted metal & Grain boundary Analysis & 90.35 & 0.94 & 0.78 & 0.25 & 1.23 & 6.44 \\
\hline HAZ & General analysis & $89.53-90.23$ & 1.06 & $0.42-0.53$ & $0.24-0.36$ & $1.52-2.21$ & $6.42-6.43$ \\
\hline HAZ & Analysis in grain volume & $91.35-92.65$ & $0.77-0.90$ & 0.72 & 0.13 & $0.66-1.32$ & $5.07-5.72$ \\
\hline HAZ & Grain boundary Analysis & 86.43 & 1.27 & 0.4 & 0.12 & 2.91 & 8.87 \\
\hline Base metal & General analysis & $89.81-91.10$ & $0.97-1.09$ & $0.23-0.71$ & $0.12-0.32$ & $1.30-1.68$ & $5.85-6.64$ \\
\hline Base metal & Analysis in grain volume & $89.96-90.74$ & $0.98-1.28$ & $0.26-0.68$ & $0.16-0.28$ & $1.42-1.62$ & $6.12-6.56$ \\
\hline
\end{tabular}

The ingress of air from the joint between the welded plates and the relatively long lifetime of the welding bath ( $0.4 \mathrm{~s})$ during microplasma welding provokes the formation of large cavities in the root part of the metal seam.

\section{3. Laser-microplasma welding}

With hybrid laser-microplasma welding, a welding bath is formed on the surface of the connected parts with a multipolar asymmetric current under the influence of a compressed arc. The presence of molten metal contributes to an increase in the proportion of absorbed laser radiation, and the electric arc stabilizes the vapor-gas channel. The use of a compressed low-ampere arc of multipolar asymmetric current makes it possible to effectively destroy the oxide film on the surface of the welded aluminum alloys, which in turn eliminates the possibility of undestroyed particles of this film entering the seam. Due to the use of additional arc energy in hybrid laser-microplasma welding, the width of the seams increases compared to laser welding with radiation of the same power. The large width of the seam allows one to reduce the requirements for the size of the gaps of the joint assembled for welding and is guaranteed to receive high-quality seams when performing hermetic connections of parts. In the experiments conducted, the depth of penetration was $0.55 \ldots 0.56 \mathrm{~mm}$; width $-1.0 \ldots 1.1 \mathrm{~mm}$ (Fig. 8, $a$ ). The fusion line is expressed quite clearly but at large magnifications it can be considered as a zone of about 15...20 $\mu \mathrm{m}$ (Fig. 8, $b$ ).

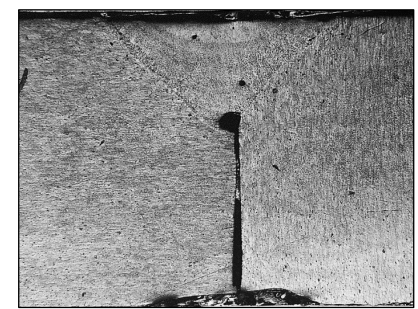

a

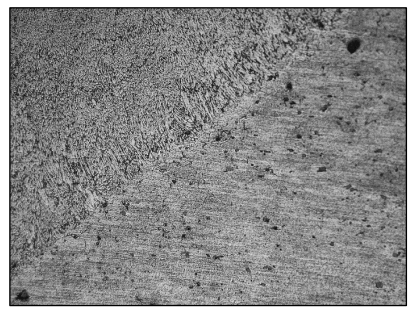

$b$
Fig. 8. Structures of laser-microplasma penetration: $a$-general view, $\times 50 ; b-$ fusion zone with base metal, $\times 250$

In the melted metal, individual pores with a diameter of 15...25 $\mu \mathrm{m}$ (Fig. 9, $a$ ) are observed. At the root of the seam, a rounded cavity with a diameter of about $100 \mu \mathrm{m}$ is identified (Fig. 9, $b$ ). Microcracks around the cavity were not observed. In the central part of the melted metal, there is a dispersed structure of equiaxial shape with a grain size of $D g=5 \ldots 15 \mu \mathrm{m}$ (Fig. 9, $a$ ). The microhardness in the center of the seam is $H V=896 \ldots 1180 \mathrm{MPa}$ (Fig. 10). Closer to the fusion line in the melted metal there is a structure of elongated shape with a grain size of $D g=(5 \ldots 10) \times(15 \ldots 60) \mu \mathrm{m}$ and hardness $H V=876 \ldots 916 \mathrm{MPa}$ (Fig. 9, $b, 10,11$ ). In the metal of the seam, single inclusions of a globular shape with a size of $15 \ldots 25 \mu \mathrm{m}$ (Fig. 9, $b$ ) are found.

The width of HAZ is $h_{H A Z}=140 \ldots 200 \mu \mathrm{m}$. The grain size in HAZ is $D g=(5 \ldots 10) \times(20 \ldots 50) \mu \mathrm{m}$ (Fig. 11), and the microhardness increases compared to the melted metal to $H V=876 \ldots 916 \mathrm{MPa}$ (Fig. 10). In the area of connection of the two plates of alloy 7075, the size of the metal grains is: for the left plate, $D g=(5 \ldots 15) \times(20 \ldots 30) \mu \mathrm{m}$, and, for the right plate, $D g=(5 \ldots 6) \times(20 \ldots 30) \mu \mathrm{m}$.

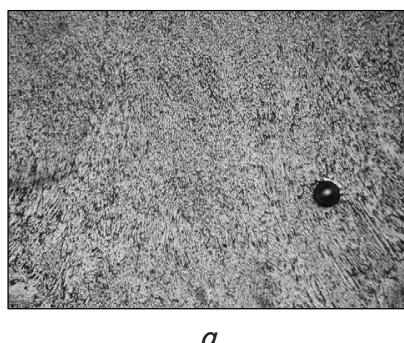

a

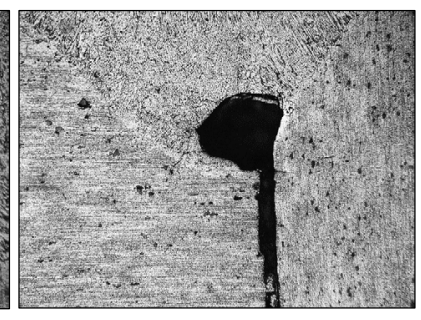

$b$
Fig. 9. Defective areas in the metal melted by the lasermicroplasma technique $(\times 250): a-$ individual pores; $b$ - cavity in the root zone

$\mathrm{X}$-ray spectral microanalysis of the content of individual elements in the metal of the compound and the base metal was carried out integrally according to the area of the corresponding zone, as well as locally in the volume of individual grains and along their boundaries (Table 5 ).

Both integral and local studies have shown that the content of the analyzed elements in the melted metal and in HAZ is approximately at the level of the base metal. In the melted metal, a slight (about $2 \%$ ) decrease in the $\mathrm{Zn}$ content can be noted, and in HAZ - its increase by $\sim 7 \%$. In the melted metal, individual inclusions with a high content of $\mathrm{Cu}(3.83 \%)$ and $\mathrm{Zn}(13.59 \%)$ were revealed. Various inclusions were also identified in HAZ: some with a high content of $\mathrm{Mg}(3.57 \%)$, Si $(4.25 \%), \mathrm{Cu}(3.74 \%)$, and $\mathrm{Zn}(10.65 \%)$, others with a high content of $\mathrm{Mg}(3.11 \%), \mathrm{Mn}(2.35 \%), \mathrm{Cu}(4.82 \%)$, Zn (13.59\%), and Cr (12.57\%). 


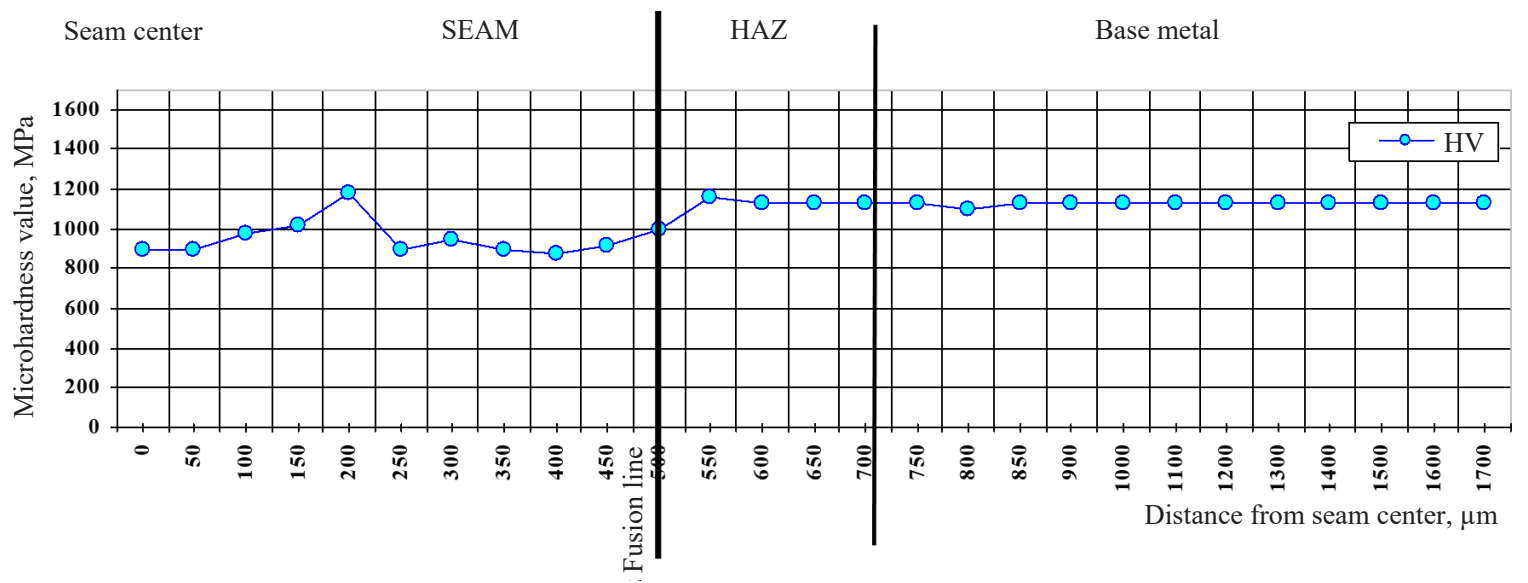

Fig. 10. Hardness distribution from the penetration axis towards the base metal in a joint made by laser-microplasma technique

Table 5

Results of determining the content of the main elements by X-ray spectral microanalysis (laser-microplasma welding)

\begin{tabular}{|c|c|c|c|c|c|c|c|}
\hline \multirow{2}{*}{ Study area } & \multirow{2}{*}{ Analysis type } & \multicolumn{5}{|c|}{ Elemental content. wt \% } \\
\cline { 3 - 8 } & & $\mathrm{Al}$ & $\mathrm{Mg}$ & $\mathrm{Si}$ & $\mathrm{Mn}$ & $\mathrm{Cu}$ & $\mathrm{Zn}$ \\
\hline Remelted metal & General analysis & $90.26-90.58$ & $1.0-1.08$ & $0.54-0.89$ & 0.09 & $1.62-1.93$ & $5.89-5.98$ \\
\hline Remelted metal & Analysis in grain volume & 90.34 & 0.89 & 0.74 & 0.06 & 1.67 & 6.3 \\
\hline Remelted metal & Grain boundary Analysis & 90.37 & 0.88 & 0.70 & 0.14 & 1.78 & 6.12 \\
\hline HAZ & General analysis & $88.55-89.76$ & $1.03-1.07$ & $0.64-0.82$ & $0.07-0.21$ & $1.72-1.97$ & $6.59-6.75$ \\
\hline HAZ & Analysis in grain volume & 89.76 & 1.18 & 0.77 & 0.16 & 1.62 & 6.51 \\
\hline HAZ & Grain boundary Analysis & 89.34 & 1.12 & 0.76 & 0.08 & 2.02 & 6.68 \\
\hline Base metal & General analysis & $90.21-90.37$ & $1.01-1.23$ & $0.60-0.95$ & $0.06-0.10$ & $1.71-1.96$ & $5.84-6.25$ \\
\hline Base metal & Analysis in grain volume & 89.76 & 0.95 & 0.68 & 0.16 & 1.91 & 6.43 \\
\hline
\end{tabular}
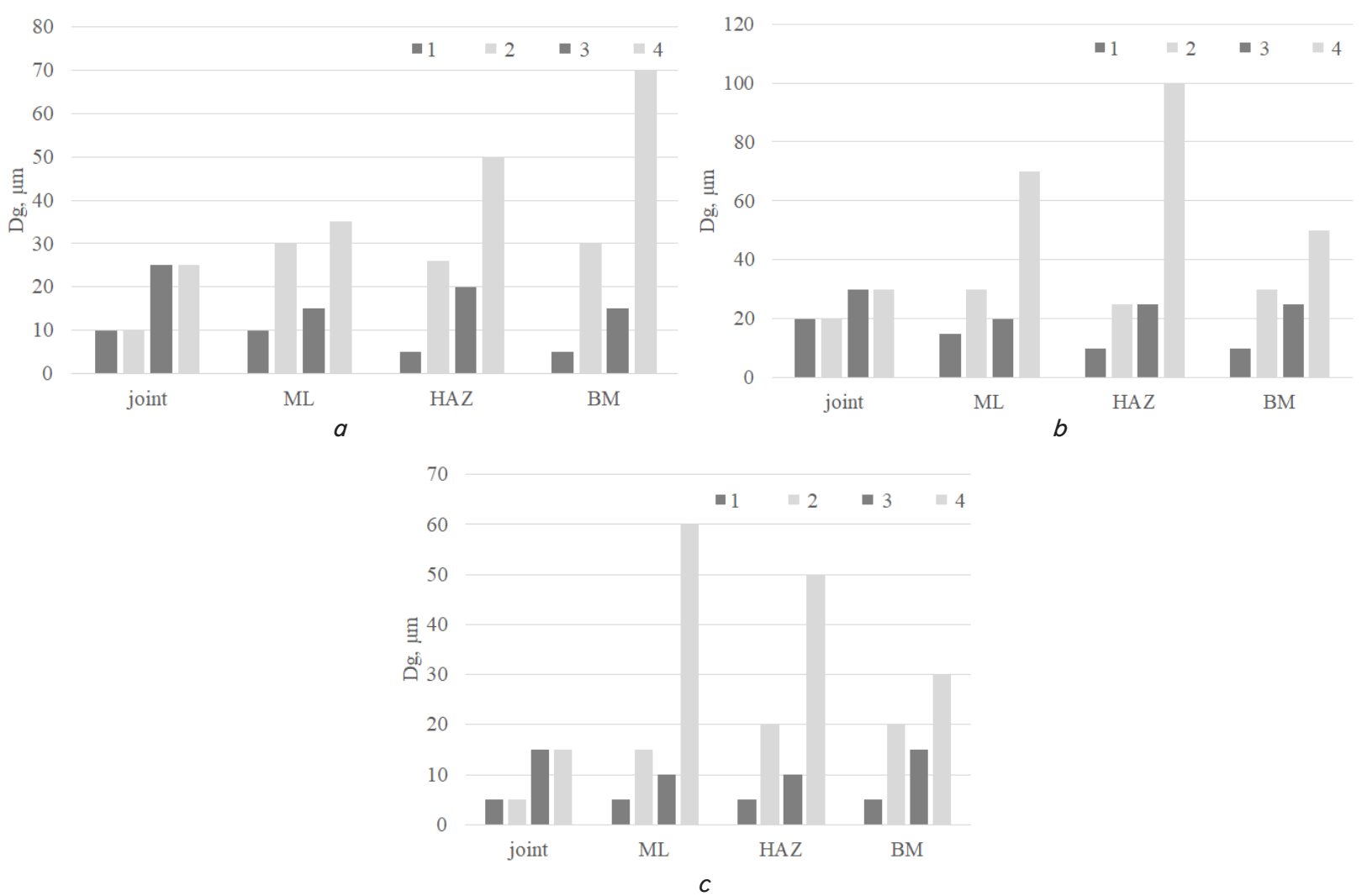

Fig. 11. Grain size $(D g=/ \times h[\mu \mathrm{m}]$, where $h-1$ and $3, /-2$ and 4$)$ in the melted metal (joint), in the fusion zone (ML), in HAZ and base metal (BM) for compounds made by the following techniques:

$a$ - laser; $b$ - microplasma; $c$ - laser-microplasma 
Comparison of the change in the size of the grain structure with different welding techniques may indicate the absence of a direct connection with cracking. The lack of the possibility of the through passage of laser radiation during hybrid laser-microplasma welding, despite the short lifetime of the welding pool $(0.03 \ldots 0.05 \mathrm{~s})$ provokes the formation of cavities in the root part of the metal of the seam.

\section{Discussion of results of the application of various techniques to form the compounds of aluminum alloy 7075}

In our studies into the content of alloying elements, it was found that with all types of welding in the seams and HAZ there is some redistribution of them. Thus, during laser welding, according to integral indicators, the content of $\mathrm{Cu}$ increases in the melted metal (by $\sim 15 \%$ ), and in the metal of $\mathrm{HAZ}-\mathrm{Cu}(\mathrm{by} \sim 15 \%)$ and Zn (8...10\%). In microplasma welding, the content of the analyzed elements in the melted metal and HAZ is approximately at the level of the base metal. In the melted metal, local inclusions with a high content of $\mathrm{Mg}(2.12 \ldots 2.23 \%), \mathrm{Cu}(3.28 \ldots 6.44 \%), \mathrm{Zn}(16.38 \ldots 30.55 \%)$ are observed. In laser-microplasma welding, the content of the analyzed elements in the remelted metal and HAZ is approximately at the level of the base metal. The exceptions are a decrease in the $\mathrm{Zn}$ content (about $2 \%$ ) in the melted metal and its increase (by $\sim 7 \%$ ) in HAZ. In the melted metal and $\mathrm{HAZ}$, individual inclusions with a high content of $\mathrm{Mg}, \mathrm{Si}$, $\mathrm{Mn}, \mathrm{Cu}, \mathrm{Zn}$, and $\mathrm{Cr}$ were revealed.

Our results can be explained by dissolution with redistribution at the integral level and/or redistribution within the grain boundaries of the inclusions present in the main metal. Recall that in the grains of the base metal we found inclusions of such elements as $\mathrm{Mg}, \mathrm{Si}, \mathrm{Mn}, \mathrm{Cu}, \mathrm{Zn}, \mathrm{Cr}$, Fe, with significant deviations from the passport data (Table 1). The practical absence of a decrease in the content of alloying elements (primarily $\mathrm{Mg}$ and $\mathrm{Zn}$ ) indicates the absence of their burnout under the action of concentrated heat sources used. This is due to the high process speeds and the short lifetime of the welding pool with laser $(0.02 \ldots 0.04 \mathrm{~s})$ and laser-microplasma $(0.03 \ldots 0.05 \mathrm{~s})$ welding.

Studies into the granularity of the resulting structures have shown that during laser welding, the size of the grains in the seam metal is approximately the same $(D g=10 \ldots 25)$, along the fusion line, the shape coefficient $\rightsquigarrow=2 \ldots 3$, in HAZ $æ=2.5 \ldots 5$ (Fig. 11, $a$ ). In microplasma welding, the grains in the central part of the melted metal have an equal-axis shape with a size of $D g=20 \ldots 30 \mu \mathrm{m}$ (Fig. 11, $b$ ).Closer to the fusion line in the melted metal, a structure with more elongated grains is observed, having a coefficient of shape $\rightsquigarrow=2 \ldots 3.5$. Along the fusion line, a gradient grain-sized structure is formed with a grain shape coefficient of up to $æ=5 \ldots 7.5$. In laser-microplasma welding, the grains in the central part of the remelted metal have an equal-axis shape with a size of $D g=5 \ldots 15 \mu \mathrm{m}$ (Fig. 11, c). Closer to the fusion line in the melted metal, a structure with more elongated grains having a shape coefficient of $\mathfrak{\varpi}=3 \ldots 6$ is observed. In HAZ, the grain shape coefficient is $\rightsquigarrow=4 \ldots 5$.

Our results regarding the shape and size of the grains in the melted metal of the seams are explained by the rather high crystallization rates of the liquid metal of the welding pool. The size and shape of the grains in HAZ depends in part on their parameters in the main metal. In it, the spread in grain sizes is up to 1.5 times or more, according to the grain shape coefficient $\nsim=2.5 \ldots 3,5$ (Fig. 11).

Studies of microhardness in the seams and HAZ have shown that with laser welding in melted metal closer to the fusion line, the hardness decreases by $10 . .15 \%$. In HAZ, the hardness of the metal increases by about $8 . . .12 \%$. This is due to the rigid thermal cycle of laser welding, the short lifetime of the welding pool $(0.02 \ldots 0.04 \mathrm{~s})$ and the value of the linear energy $(5 \mathrm{~J} / \mathrm{mm})$. In microplasma welding, in comparison with the base metal, the microhardness of the remelted zone is reduced by $15 \ldots 30 \%$. In HAZ, the microhardness roughly corresponds to the base metal. This is due to a significantly higher linear energy $(120 \mathrm{~J} / \mathrm{mm})$ compared to laser welding. With laser-microplasma welding, in comparison with the base metal, the microhardness of the remelted zone is reduced by $15 . .20 \%$, there are separate areas without reducing the hardness. In HAZ, the microhardness roughly corresponds to the base metal. This is due to three times the running energy $(15 \mathrm{~J} / \mathrm{mm})$ compared to laser welding. Note that the base metal has a variation in hardness values of up to $10 \%$.

The study of the presence of characteristic defects showed the following. In laser welding, the total volumetric fraction of defects (mainly $10 \ldots 30 \mu \mathrm{m}$ ) in the melted metal is on the order of $V_{D} \sim 5 \%$. In the lower third of the melted metal, there is a cavity measuring approximately $25 \times 100 \mu \mathrm{m}$, which serves as the center of the origin of hot cracks with a length of $L_{c r}=25 \ldots 30 \mu \mathrm{m}$. The formation of this cavity is explained by both the ingress of gas from the welded joint and the lack of free output of laser radiation. The gas forms bubbles that do not have time to surface due to small quantities of linear energy $(5 \mathrm{~J} / \mathrm{mm})$ and the lifetime of the liquid metal bath (about $0.02 \ldots 0.04 \mathrm{~s}$ ). Laser radiation that does not have a free outlet forms the particle structure of the seam root described in the literature (for example, work [16]), which contributes to the occurrence of root porosity.

In the root zone of the melted metal, oxide film secretions were revealed, repeating the fusion line in shape (Fig. 3, $a$ ). These are string-type selections with a size $l_{\mathrm{Al}_{2} \mathrm{O}_{3}}=25 \ldots 35 \mu \mathrm{m}$ arranged in the form of chains up to $L_{\mathrm{SAl}_{2} \mathrm{O}_{3}}=50 \ldots 120 \mu \mathrm{m}$. Their location is associated with hydrodynamic flows in the bath of liquid metal.

An increase in the hardness in HAZ by $8 . . .12 \%$ in combination with the grain structure described above explains the formation of individual microcracks with a length of $L_{c r}=10 \ldots 20 \mu \mathrm{m}$ in the HAZ near the fusion line (Fig. 3, $b$ ). The formation of these microcracks can also be explained by the relaxation of internal residual stresses.

In microplasma welding, the total volumetric fraction of defects (mainly pores of $10 \ldots 105 \mu \mathrm{m}$ ) in the melted metal is on the order of $V_{D^{\sim}} 25 \%$ (Fig. $6, a$ ). In the lower part of the melted metal there is a cavity with a variable (in various sections of the seam) diameter from 90 to $260 \mu \mathrm{m}$ (Fig. 6, $b$ ). This cavity initiates the nucleation of microcracks with a length of $L_{c r}=30 \ldots 120 \mu \mathrm{m}$. Its presence is explained by the ingress of air from the welded joint. The longer existence of a melt bath, compared to laser welding, leads to an increase in the size of this gas cavity. Traces of the oxide film were not revealed, since a microplasma arc with multipolar pulses was used. In this case, the pulses of reverse polarity carried out the cathodic destruction of the oxide film.

In laser-microplasma welding, the total volumetric fraction of defects (mainly pores of size $15 . .25 \mu \mathrm{m}$ ) in the melted metal is up to $V_{D} \sim 5 \%$. In the root zone of the melted metal, a cavity is observed, the size of which in various cross- 
sections varies from a round $100 \times 100 \mu \mathrm{m}$ to an oblong $30 \times 100 \mu \mathrm{m}$ (Fig. 9, $b$ ). The formation of a cavity, as in previous cases, is explained by the ingress of air from the welded joint. Bubbles are formed that do not have time to surface due to the short lifetime of the molten metal bath $(0.03 \ldots 0.05 \mathrm{~s})$. Traces of oxide film were not detected because, as in the case of microplasma welding, there was a cathode destruction of the oxide film.

A distinctive feature of the applied research techniques is to establish a connection between the formation of microcracks in the seams with their granular structure, the hardness of the connection zones, and the formation of root defects (cavities). Usually, for welding aluminum alloys, $\mathrm{Al}-\mathrm{Zn}-\mathrm{Mg}-\mathrm{Cu}$ systems in the literature describe the relationship of the formation of microcracks in the seams with the heat addition and parameters of welding modes. The main limitation of the studies performed is the consideration of only three techniques of welding. In the future, it is advisable to consider open arc welding of the melting and non-melting electrodes, as well as the corresponding hybrid laser arc processes.

An advancement of this study is the use of the laser-microplasma technique of welding both high-strength alloy 7075 and other alloys of the $7 \mathrm{xxx}$ series. This approach could provide for the following:

- to achieve the lowest dispersion of grains in the seams and HAZ

- to eliminate the hardness increases characteristic of laser welding in HAZ and the tendency to form microcracks in it;

- due to the effect of cathodic destruction of the oxide film, eliminate the danger of its inclusions in the seam metal;

- to increase the efficiency of the process by reducing the use of laser energy by $40 . .50 \%$ compared to laser welding;

- to increase the speed of the process by more than an order of magnitude compared to microplasma welding;

- to bring closer the linear energy $(15 \mathrm{~J} / \mathrm{s})$ and the lifetime of the welding pool $(0.03 \ldots 0.05 \mathrm{~m})$ to similar indicators of laser welding without the danger of burnout of alloying elements.

Further improvement of the quality of welded joints of high-strength aluminum alloys obtained by sealed nonthrough seams is possible due to the introduction of some structural changes. For example, in the joint below the root part of the future seam, one can provide a technological cavity, the so-called «pocket». This technique will contribute to the free output of laser radiation during laser or hybrid laser-microplasma welding. This would make it possible to eliminate the formation of a pore at the root of the seam.

\section{Conclusions}

1. It is established that laser welding of butt joints of aluminum alloy 7075 makes it possible to obtain sufficiently narrow (up to $0.74 \mathrm{~mm}$ ) seams with minimal costs of linear energy $(5 \mathrm{~J} / \mathrm{mm})$ and the time of existence of the melt bath $(0.02 \ldots 0.04 \mathrm{~s})$. The granularity of the compound is regular, the grains are equiaxial in the melted metal and elongated along the fusion line $(\boldsymbol{\infty}=2 \ldots 3)$ and in HAZ $(\boldsymbol{\infty}=2.5 \ldots 5)$. Microhardness in the seams is reduced to $15 \%$, and in HAZ it increases by $8 . .12 \%$ relative to the base metal. The main defects are the formation of microcracks in HAZ with a length of $10 \ldots 20 \mu \mathrm{m}$ and the presence in the root part of the seams of inclusions of an undestroyed oxide film.

2. It is established that microplasma welding of alloy 7075 joints on alternating asymmetric current is characterized by an increase in the width of the seam up to 2.5 times compared to laser. The magnitude of the granularity of the compound increases. In the melted metal, the equiaxial structure of the grain structure is preserved, while the size of the grains themselves increases by 1.5 times, compared with laser welding. Along the fusion line and in the HAZ, structures with elongated grains are formed $(\mathfrak{\infty}=5 \ldots . .7 .5$ and $\mathfrak{\infty}=2 \ldots .3 .5$, respectively $)$. The microhardness of HAZ roughly corresponds to the base metal. Microcracks in HAZ and oxide inclusions in the melted metal were not detected. The main defect is a decrease in the microhardness, and hence the strength, of the seam metal to $30 \%$.

3. To eliminate the detected defects, it is proposed to use hybrid laser-microplasma welding. The width of the seams with such welding is $\sim 1.5$ times less than with microplasma. The grain structure of the melted metal has an equal-axis structure, the size of the grains is reduced by 1.5-2 times compared to laser welding. Along the fusion line and in the HAZ, structures with elongated grains are formed $(\mathfrak{\infty}=3 \ldots 6$ and $\mathfrak{x}=4 \ldots 5$, respectively). The microhardness of the melted metal is reduced to $15 \ldots 20 \%$, and, in HAZ, roughly corresponds to the base metal. At the same time, the use of expensive laser energy is reduced by $40 \ldots 50 \%$, the lifetime of the welding pool $(0.03 \ldots 0.05 \mathrm{~s})$ approaches laser welding, eliminates the danger of burnout of alloying elements.

\section{Acknowledgments}

We express our deep gratitude to PhD S. Grigorenko, Head of the Department «Physical and Chemical Research of Materials», as well as employees of this department. First of all, PhD O. Kushnareva, who was directly involved in the research.

\section{References}

1. Varshney, D., Kumar, K. (2021). Application and use of different aluminium alloys with respect to workability, strength and welding parameter optimization. Ain Shams Engineering Journal, 12 (1), 1143-1152. doi: https://doi.org/10.1016/j.asej.2020.05.013

2. Löveborn, D., Larsson, J. K., Persson, K.-A. (2017). Weldability of Aluminium Alloys for Automotive Applications. Physics Procedia, 89, 89-99. doi: https://doi.org/10.1016/j.phpro.2017.08.011

3. Schubert, E. (2018). Challenges in Thermal Welding of Aluminium Alloys. World Journal of Engineering and Technology, 06 (02), 296-303. doi: https://doi.org/10.4236/wjet.2018.62018

4. Krivtsun, I. V., Khaskin, V. Y., Korzhik, V. N., Ziyi, L. (2015). Industrial application of hybrid laser-arc welding (Review).The Paton Welding Journal, 2015 (7), 41-46. doi: https://doi.org/10.15407/tpwj2015.07.07

5. Zacharia, T., David, S. A., Vitek, J. M., Debroy, T. (1990). Modeling of interfacial phenomena in welding. Metallurgical Transactions B, 21 (3), 600-603. doi: https://doi.org/10.1007/bf02667874

6. Tanaka, M., Ushio, M., Lowke, J. J. (2005). Numerical Analysis for Weld Formation Using a Free-Burning Helium Arc at Atmospheric Pressure. JSME International Journal Series B, 48 (3), 397-404. doi: https://doi.org/10.1299/jsmeb.48.397 
7. Borisov, Yu. S., Demchenko, V. F., Lesnoj, A. B., Khaskin, V. Yu., Shuba, I. V. (2013). Numerical modelling of heat transfer and hydrodynamics in laser-plasma treatment of metallic materials. The Paton Welding Journal, 4, 2-7.Available at: https://www.researchgate.net/publication/283796313_Numerical_Modelling_of_Heat_Transfer_and_Hydrodynamics_in_Laser-Plasma_Treatment_of_Metallic_Materials

8. Holzer, M., Hofmann, K., Mann, V., Hugger, F., Roth, S., Schmidt, M. (2016). Change of Hot Cracking Susceptibility in Welding of High Strength Aluminum Alloy AA 7075. Physics Procedia, 83, 463-471. doi: https://doi.org/10.1016/j.phpro.2016.08.048

9. Behler, K., Berkmanns, J., Ehrhardt, A., Frohn, W. (1997). Laser beam welding of low weight materials and structures. Materials \& Design, 18 (4-6), 261-267. doi: https://doi.org/10.1016/s0261-3069(97)00085-x

10. Gündoğduİș, E., Akman, E., Yilmaz, M., Topuz, P. (2020). Effect of laser welding speed on pore formation in AA 6061 T6 alloy. Materials Testing, 62 (10), 979-984. doi: https://doi.org/10.1515/mt-2020-621004

11. Hagenlocher, C., Weller, D., Weber, R., Graf, T. (2018). Reduction of the hot cracking susceptibility of laser beam welds in AlMgSi alloys by increasing the number of grain boundaries. Science and Technology of Welding and Joining, 24 (4), 313-319. doi: https:// doi.org/10.1080/13621718.2018.1534775

12. Olabode, M., Kah, P., Martikainen, J. (2013). Aluminium alloys welding processes: Challenges, joint types and process selection. Proceedings of the Institution of Mechanical Engineers, Part B: Journal of Engineering Manufacture, 227 (8), 1129-1137. doi: https://doi.org/10.1177/0954405413484015

13. Kang, M., Kim, C. (2017). A Review of Joining Processes for High Strength 7xxx Series Aluminum Alloys. Journal of Welding and Joining, 35 (6), 79-88. doi: https://doi.org/10.5781/jwj.2017.35.6.12

14. Cao, X., Wallace, W., Immarigeon, J.-P., Poon, C. (2003). Research and Progress in Laser Welding of Wrought Aluminum Alloys. II. Metallurgical Microstructures, Defects, and Mechanical Properties. Materials and Manufacturing Processes, 18 (1), $23-49$. doi: https://doi.org/10.1081/amp-120017587

15. Korzhyk, V. M., Khaskin, V. Y., Grynyuk, A. A., Illyashenko, E. V., Bernatskyi, A. V., Peleshenko, S. I. (2021). Features of laser-plasma welding of corrosion-resistant steel AISI 304 with laser application. The Paton Welding Journal, 2021 (12), 9-17. doi: https:// doi.org/10.37434/tpwj2021.12.02

16. Fetzer, F., Hu, H., Berger, P., Weber, R., Eberhard, P., Graf, T. (2018). Fundamental investigations on the spiking mechanism by means of laser beam welding of ice. Journal of Laser Applications, 30 (1), 012009. doi: https://doi.org/10.2351/1.4986641 